\title{
Hypertension-susceptibility gene prevalence in the Pacific Islands and associations with hypertension in Melanesia
}

\author{
Takuro Furusawa ${ }^{1}$, Izumi Naka ${ }^{2}$, Taro Yamauchi ${ }^{3}$, Kazumi Natsuhara $^{4}$, Ricky Eddie ${ }^{5}$, Ryosuke Kimura ${ }^{6}$, \\ Minato Nakazawa ${ }^{7}$, Takafumi Ishida ${ }^{8}$, Tsukasa Inaoka ${ }^{9}$, Yasuhiro Matsumura ${ }^{10}$, Yuji Ataka ${ }^{11}$, \\ Ryutaro Ohtsuka ${ }^{12}$ and Jun Ohashi ${ }^{2}$
}

Human essential hypertension is partly caused by genetic factors. Angiotensinogen (AGT), G-protein $\beta 3$-subunit (GNB3) and cytochrome P450 3A5 (CYP3A5) are candidate hypertension susceptibility genes and risk alleles at these loci have been thought to arise owing to human adaptation to climatic changes following the migration out-of-Africa. This study aimed to reveal the frequencies of hypertension-susceptibility genotypes in Pacific Island populations and associations of these single-nucleotide polymorphisms (SNPs) to hypertension. Genotyping was conducted for 804 individuals from Melanesian, Micronesian and Polynesian populations at SNPs in the genes encoding AGT (rs699, rs5049 and rs5051), GNB3 (rs5443) and $C$ YP $3 A 5^{*} 1{ }^{*} 3$ (rs776746). Associations between these SNPs and hypertension were tested for 383 Melanesian Solomon Islanders. We found that the A/A genotype at rs5049 was a risk factor for hypertension $(P=0.025)$ in the Melanesian Solomon Islanders; three SNPs for $A G T$ were in linkage disequilibrium. The ancestral alleles of rs699, rs5051 and rs776746, and the derived allele of rs 5443 were as frequent in the populations surveyed here as in other equatorial populations. Although other polymorphisms associated with hypertension and additional populations remain to be studied, these findings suggest that the Pacific Islanders' susceptibility to hypertension arose because of human migration and adaptation. Journal of Human Genetics (2013) 58, 142-149; doi:10.1038/jhg.2012.147; published online 17 January 2013

Keywords: blood pressure; C825T; G-217A; G-6A M235T

\section{INTRODUCTION}

Human essential hypertension, which is a major risk factor for stroke, ischemic heart diseases, myocardial infarction, heart failure, aneurism and chronic renal failure, has become one of the greatest health concerns in the world. ${ }^{1}$ Its prevalence is rapidly increasing in developing countries of the Asia Pacific region, associated with drastic changes in lifestyle; ${ }^{2,3}$ candidate environmental factors include high dietary intake of sodium and alcohol, obesity and stress. $^{1}$ In addition, several genetic factors have been reported. Angiotensinogen (AGT) is a key component of the reninangiotensin system, which influences all aspects of blood pressure, including blood vessel contraction, sodium and water balance, and cell development in the heart. ${ }^{4}$ G-protein $\beta 3$-subunit (GNB3) has essential roles in G-protein-coupled receptor-related signal transduction pathways involved in blood pressure regulation. The cytochrome P450 3A5 (CYP3A5) enzyme metabolizes cortisol and is related to sodium transport in renal epithelia, increasing sodium and water retention, and blood pressure. ${ }^{5}$ Genes encoding $\alpha$-adducin, $\beta_{2}$-adrenergic receptor and angiotensin-converting enzyme inhibitor are also candidates. ${ }^{6}$

It has been hypothesized that susceptibility to hypertension is influenced by ancestral traits, because several known risk factors, such

${ }^{1}$ Graduate School of Asian and African Area Studies, Kyoto University, Kyoto, Japan; ${ }^{2}$ Doctoral Program in Life System Medical Sciences, Graduate School of Comprehensive Human Sciences, University of Tsukuba, Ibaraki, Japan; ${ }^{3}$ Graduate School of Health Sciences, Hokkaido University, Hokkaido, Japan; ${ }^{4}$ The Japanese Red Cross Akita College of Nursing, Akita, Japan; ${ }^{5}$ National Gizo Hospital, Ministry of Health and Medical Services, Gizo, The Solomon Islands; ${ }^{6}$ Transdisciplinary Research Organization for Subtropical and Island Studies (TRO-SIS), University of the Ryukyus, Okinawa, Japan; 7 Department of International Health, Kobe University Graduate School of Health Sciences, Kobe, Japan; ${ }^{8}$ Department of Biological Sciences, Graduate School of Science, The University of Tokyo, Tokyo, Japan; ${ }^{9}$ Department of Human Ecology, Faculty of Agriculture, Saga University, Saga, Japan; ${ }^{10}$ Faculty of Health and Nutrition, Bunkyo University, Kanagawa, Japan; ${ }^{11}$ School of Policy Studies, Kwansei Gakuin University, Hyogo, Japan and ${ }^{12}$ Japan Wildlife Research Center, Tokyo, Japan

Correspondence: Dr T Furusawa, Graduate School of Asian and African Area Studies, Kyoto University, Room \#AA431, Research Building No. 2, Yoshida-Honmachi, Sakyo-ku, Kyoto 606-8501, Japan.

E-mail: takuro.f@gmail.com

or Dr J Ohashi, Doctoral Program in Life System Medical Sciences, Graduate School of Comprehensive Human Sciences, University of Tsukuba, 1-1-1 Tennodai, Tsukuba, Ibaraki 305-8575, Japan.

E-mail: juno-tky@umin.ac.jp

Received 6 July 2012; revised 20 November 2012; accepted 22 November 2012; published online 17 January 2013 
as enhanced salt and water avidity and vascular reactivity, are adaptive traits associated with hot and humid environments of the ancestral African climate. ${ }^{7}$ In addition, previous studies have suggested that particular genotypes, associated with susceptibility to elevated blood pressure, are rather prevalent in geographic regions near the equator and/or with high temperatures and precipitation, implicating a role for natural selection during the out-of-Africa migration. ${ }^{8}$ For example, a study of single-nucleotide polymorphisms (SNPs) in the AGT gene suggested that ancestral genotypes of rs699 (M235T) and rs5051 ( $\mathrm{G}-6 \mathrm{~A})$, which had also been found in non-human primates, were frequently found even in non-African populations in tropical regions of Asia and America. ${ }^{8,9}$ The frequencies of ancestral genotypes in the CYP3A $5^{*} 11^{*} 3$ (rs776746) and AGT (rs699) genes decrease as the distance from the equator increases. ${ }^{10}$ In contrast, the derived allele of C825T (rs5443) in GNB3, which is present only in humans and thus seems to be a newly derived allele, has been reported to occur frequently in low-latitude, particularly in Africa; ${ }^{8}$ the derived allele of $\mathrm{G}-217 \mathrm{~A}$ ( $\mathrm{rs} 5049$ ) in $A G T$, which is also present only in humans, was not associated with latitude in populations worldwide, but was positively correlated within the African populations. Young et $a .^{8}$ also reported that other SNPs or short tandem repeat polymorphisms, which they analyzed, was less strongly associated with latitude than rs5051 or rs5443. These findings suggest that hypertension is a 'thrifty' trait; ${ }^{11}$ that is, individuals with genotypes associated with improved survival during salt scarcity and low food availability are at a high risk of hypertension in an environment with a high availability of salt and a high-calorie diet. Thus, understanding the underlying genetic variation at loci associated with susceptibility to elevated blood pressure could contribute to our understanding of human evolution under various climatic environments.

The Pacific Islands represent one of the regions of the world that were most recently settled by migrating humans. Linguistic, archeological and genetic studies have suggested that Austronesian (AN)speaking populations who migrated from continental Asia, passed through the islands of Southeast Asia and Melanesia; arrived in Polynesia <2000 years ago; and now inhabit in Polynesia, Micronesia and parts of Melanesia. ${ }^{12-15}$ Note that the majority of the population of New Guinea and its neighboring islands in Melanesia are Non-AN (NAN)-speaking, and these regions are home to potential descendants of the first human population who settled in this area 50-30000 years ago; this population, in contrast to $\mathrm{AN}$-speaking populations, did not further migrate from Melanesia to Polynesia or Micronesia likely because they did not develop technologies for long voyages. The AN-speaking population is a candidate population with the thrifty genotype because they have experienced frequent starvation during inter-island voyages ${ }^{16,17}$ while adapting to the climate. Hypertension prevalence is potentially related to both genetic and environmental factors. ${ }^{2,3,18,19}$ In particular, previous studies have suggested that the hypertension was more prevalent in the AN-speaking Melanesians than AN-speaking Micronesians. ${ }^{2,18}$ However, few detailed studies on genotypes associated with hypertension have been conducted in populations of the AN-speaking Melanesians.

This study aimed to reveal the frequencies of hypertension susceptibility genotypes in Pacific Island populations (Melanesians, Micronesians and Polynesians). We targeted SNPs known to be related to latitude in other populations (rs699, rs5049 and rs5051 in AGT; rs5443 in GNB3; and rs776746 in CYP3A5). Special attention was thus paid to associations of these SNPs to hypertension in the Melanesian Solomon Islanders. This is the first investigation of these SNPs and their relationship to hypertension and associated phenotypes conducted in populations of the Pacific Islands.

\section{MATERIALS AND METHODS}

\section{Study populations}

Study participants were recruited from seven Pacific Islander populations: (1) AN-speaking Melanesians in Balopa, from Manus Province, Papua New Guinea; (2) Kusaghe (note that in our previous papers, named Paradise after their settlement name) in North New Georgia, Western Province of the Solomon Islands; (3) Munda, in the Western Province of the Solomon Islands; (4) AN-speaking Micronesians in Ravaki in the Western Province of the Solomon Islands; (5) AN-speaking Polynesians in Ha'apai Island; (6) Nuku'alofa, the capital of the Kingdom of Tonga; and (7) NAN-speaking Melanesians in Gidra from the Western Province of Papua New Guinea (Figure 1). Sampling was made in the biggest settlement (Kusaghe, Munda, Nuku'alofa) or by visiting two or more settlements (Balopa, Gidra, Ha’apai) in each area so as that participants represented each population. Although Ravaki village was located in the Solomon Islands, the inhabitants had migrated there from overpopulated Gilbert Islands (Kiribati) in the 1960s. All measurements and sampling were performed after obtaining informed consent from each participant. This study was approved by the Health Research Ethics Committee, the Ministry of Health and Medical Services of the Solomon Islands; the Medical Research Advisory Committee of Papua New Guinea; National Health Ethics and Research Committee of Tonga; the Research Ethics Committee of the Faculty of Medicine at the University of Tokyo; and the Graduate School of Comprehensive Human Sciences at the University of Tsukuba, Japan.

\section{Genotyping}

Blood was sampled in the field and genomic DNA was extracted using the QIAamp Blood Kit (Qiagen, Hilden, Germany). Genotyping five SNPs (rs699, rs5049, rs5051, rs5443 and rs776746) was performed using TaqMan SNP genotyping assays (Applied Biosystems, Carlsbad, CA, USA). In total, 804 individuals were examined in this study.

\section{Genotype database}

Allele frequencies and latitudes of other populations were obtained from the Allele Frequency Database (ALFRED) at Yale University (http://alfred.med. yale.edu/). Because latitudes reported in ALFRED ranged from the southernmost to the northern-most latitude inhabited by a given population, the average of this range was used for each population. Populations that were not sampled in their countries of origin (for example, African Americans, European Americans, European-origin mixed ethnicities, European New Zealanders, Japanese in the United States and Canarians) were excluded from analyses, given the possibility that the sampled locations did not reflect their potential adaptation to the climate. Data from only three populations were reported for rs5443 in ALFRED. Therefore, we also used data for rs5443 available in dbSNP through the National Center for Biotechnology Information (http://www.ncbi.nlm.nih.gov/projects/SNP/). The latitudes of the populations shown in dbSNP were identified from the information registered in ALFRED; if complete information for a given population was not available in ALFRED, the latitude was identified from Google Earth (Google Inc., Mountain View, CA, USA) based on the name of the population/location (electronic Supplementary Materials: Supplementary Tables S1-S5). The alleles were classified into ancestral or derived ones on the basis of information registered at the dbSNP (Table 1).

\section{Anthropometric and blood pressure measurements}

Anthropometric and blood pressure measurements were performed in Melanesian Solomon Islanders (Kusaghe and Munda). All participants were asked to arrive to the survey center (hospital and/or community hall) before 0900 hours. Body height was measured to the nearest $1 \mathrm{~mm}$ using a field anthropometer (GPM, Zurich, Switzerland), and weight was recorded to the nearest $0.1 \mathrm{~kg}$ using a portable digital scale (Tanita model BC-518, Tokyo, Japan), following a previously reported protocol. ${ }^{20}$ The sitting blood pressure was measured twice from the arm using a digital blood pressure monitor (HEM757, Omron, Kyoto, Japan); the average of the two values was used. Hypertension was defined as values $\geqslant 140 \mathrm{~mm} \mathrm{Hg}$ for systolic blood pressure (SBP) and/or $\geqslant 90 \mathrm{~mm} \mathrm{Hg}$ for diastolic blood pressure (DBP). Of the 399 participants, 16 were pregnant female, or had already been diagnosed with 


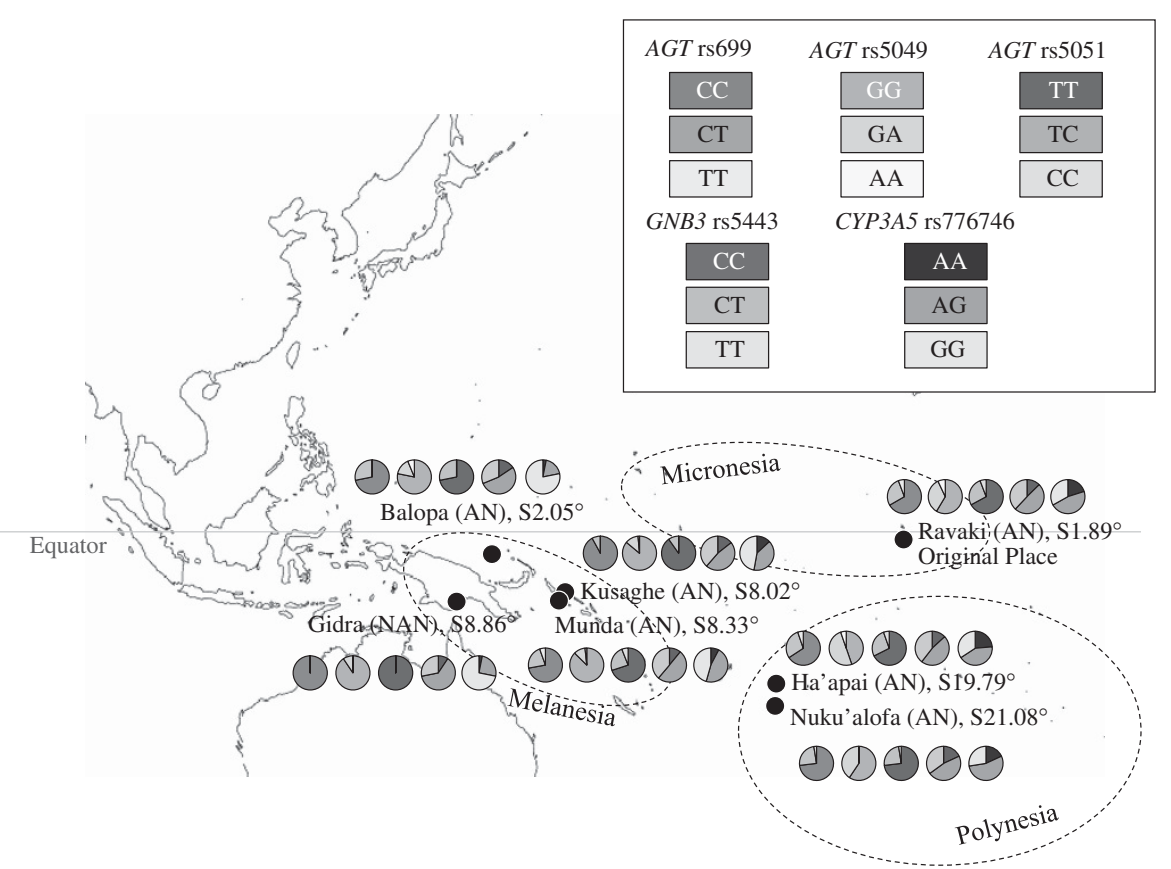

Figure 1 Locations of the study populations and the genotype frequencies for the SNPs rs699, rs5049 and rs5051 in AGT; rs5443 in GNB3; and rs776746 in CYP3A5. The ancestral alleles for each SNP are as follows: rs699-C, rs5049-G, rs5051-T, rs5443-C and rs776746-A. The Ravaki people, who originate from the Gilbert Islands, were sampled in the Solomon Islands. A full color version of this figure is available at the Journal of Human Genetics journal online.

Table 1 The allele frequencies at SNPs in AGT, GNB3 and CYP3A5 in the Pacific Island populations

\begin{tabular}{|c|c|c|c|c|c|c|c|c|c|c|c|c|c|c|c|}
\hline & \multicolumn{3}{|c|}{$\begin{array}{l}\text { AGT rs699 (M235T) } \\
\text { (ancestral = C (235T)) }\end{array}$} & \multicolumn{3}{|c|}{$\begin{array}{l}\text { AGT rs5049 }(G-217 A) \\
\text { (ancestral=G(-217G)) }\end{array}$} & \multicolumn{3}{|c|}{$\begin{array}{l}\text { AGT rs5051 }(G-6 A) \\
\text { (ancestral=T }(-6 G))\end{array}$} & \multicolumn{3}{|c|}{$\begin{array}{l}\text { GNB3 rs5443 (C825T) } \\
\text { (ancestral }=C(825 C))\end{array}$} & \multicolumn{3}{|c|}{$\begin{array}{c}\text { CYP3A5 rs776746 }\left({ }^{*} 1 /{ }^{*} 3\right) \\
\text { (ancestral }=A(* 1))\end{array}$} \\
\hline & $C / C$ & $C / T$ & $T / T$ & $G / G$ & $G / A$ & $A / A$ & $T / T$ & $T / C$ & $C / C$ & $C / C$ & $C / T$ & $T / T$ & $A / A$ & $A / G$ & $G / G$ \\
\hline Balopa & 23 & 9 & 0 & 25 & 5 & 2 & 23 & 9 & 0 & 5 & 17 & 10 & 1 & 6 & 25 \\
\hline (AN, Melanesia) & $71.9 \%$ & $28.1 \%$ & $0 \%$ & $78.1 \%$ & $15.6 \%$ & $6.3 \%$ & $71.9 \%$ & $28.1 \%$ & $0.0 \%$ & $15.6 \%$ & $53.1 \%$ & $31.3 \%$ & $3.1 \%$ & $18.8 \%$ & $78.1 \%$ \\
\hline Kusaghe & 196 & 17 & 0 & 185 & 27 & 3 & 194 & 21 & 0 & 31 & 101 & 83 & 28 & 85 & 101 \\
\hline (AN, Melanesia) & $92.0 \%$ & $8.0 \%$ & $0 \%$ & $86.0 \%$ & $12.6 \%$ & $1.4 \%$ & $90.2 \%$ & $9.8 \%$ & $0.0 \%$ & $14.4 \%$ & $47.0 \%$ & $38.6 \%$ & $13.1 \%$ & $39.7 \%$ & $47.2 \%$ \\
\hline Munda & 132 & 41 & 10 & 159 & 20 & 3 & 128 & 44 & 11 & 20 & 92 & 71 & 14 & 85 & 83 \\
\hline (AN, Melanesia) & $72.1 \%$ & $22.4 \%$ & $5.5 \%$ & $87.4 \%$ & $11.0 \%$ & $1.6 \%$ & $69.9 \%$ & $24.0 \%$ & $6.0 \%$ & $10.9 \%$ & $50.3 \%$ & $38.8 \%$ & $7.7 \%$ & $46.7 \%$ & $45.6 \%$ \\
\hline Ravaki & 104 & 43 & 9 & 92 & 54 & 11 & 104 & 42 & 9 & 20 & 78 & 60 & 31 & 72 & 51 \\
\hline (AN, Micronesia) & $66.7 \%$ & $27.6 \%$ & $5.8 \%$ & $58.6 \%$ & $34.4 \%$ & $7.0 \%$ & $67.1 \%$ & $27.1 \%$ & $5.8 \%$ & $12.7 \%$ & $49.4 \%$ & $38.0 \%$ & $20.1 \%$ & $46.8 \%$ & $33.1 \%$ \\
\hline Ha'apai & 25 & 11 & 2 & 17 & 19 & 2 & 25 & 10 & 2 & 5 & 18 & 15 & 9 & 16 & 13 \\
\hline (AN, Polynesia) & $65.8 \%$ & $28.9 \%$ & $5.3 \%$ & $44.7 \%$ & $50.0 \%$ & $5.3 \%$ & $67.6 \%$ & $27.0 \%$ & $5.4 \%$ & $13.2 \%$ & $47.4 \%$ & $39.5 \%$ & $23.7 \%$ & $42.1 \%$ & $34.2 \%$ \\
\hline Nuku'alofa & 117 & 39 & 4 & 95 & 65 & 0 & 117 & 39 & 4 & 29 & 75 & 56 & 29 & 87 & 44 \\
\hline (AN, Polynesia) & $73.1 \%$ & $24.4 \%$ & $2.5 \%$ & $59.4 \%$ & $40.6 \%$ & $0.0 \%$ & $73.1 \%$ & $24.4 \%$ & $2.5 \%$ & $18.1 \%$ & $46.9 \%$ & $35.0 \%$ & $18.1 \%$ & $54.4 \%$ & $27.5 \%$ \\
\hline Gidra & 32 & 0 & 0 & 29 & 3 & 0 & 32 & 0 & 0 & 3 & 20 & 9 & 1 & 8 & 23 \\
\hline (NAN, Melanesia) & $100 \%$ & $0 \%$ & $0 \%$ & $90.6 \%$ & $9.4 \%$ & $0 \%$ & $100 \%$ & $0 \%$ & $0 \%$ & $9.4 \%$ & $62.5 \%$ & $28.1 \%$ & $3.1 \%$ & $25.0 \%$ & $71.9 \%$ \\
\hline
\end{tabular}

Abbreviations: AN, Austronesian; NAN, Non-Austronesian; SNP, single-nucleotide polymorphism.

hypertension and treated with antihypertensive drugs; these participants were excluded from subsequent analyses. Note that, in addition to our attention on an increase of hypertension in Melanesia, a reason Melanesian Solomon Islanders only was chosen is that there was a difficulty to measure blood pressure of extremely obese participants (that is, those with larger arm circumferences than the cuff length) at a reliable level under the field-survey conditions for Micronesian and Polynesian populations.

\section{Statistical analyses}

Deviation from Hardy-Weinberg equilibrium was tested at each SNP in each population by using Peason's $\chi^{2}$-test. Associations of allele frequencies of pairs of SNPs were analyzed by using Fisher's exact test. Pearson's correlation coefficients were calculated for allele frequency data and distances of each population from the equator. Inter-population differences in hypertension prevalence were tested by using Fisher's exact test. Multiple logistic regression analysis (homozygote of ancestral allele $=1$ ) and an analyses of covariance (ANCOVA) with a Tukey's post hoc test were performed to examine the potential effects of each SNP on hypertension and SBP or DBP; in these models, age, gender $($ female $=1$, male $=0)$, body mass index $(\mathrm{BMI})$ and population differences (Munda $=1$, Kusaghe $=0$ ) were included as explanatory variables to remove confounding effects. Finally, for detecting effects of each SNP independently from other SNPs, in addition to these confounding variables, all SNPs (three in the AGT gene and one GNB3 and one CYP3A5) 
were included in the logistic regression and general linear models for which significant factors were selected in a stepwise manner; significance levels for both entry and staying were set at 0.15 . Statistical analyses were performed using SAS 9.2 (SAS Institute, Cary, NC, USA). $P$-values $<0.05$ were considered statistically significant. The haplotype frequencies for three AGT SNPs were estimated using expectation maximization algorithms; the estimated haplotype frequencies were used to calculate linkage disequilibrium parameters, $\left|D^{\prime}\right|$ and $r^{2}$, between these polymorphisms.

\section{RESULTS}

Table 1 and Figure 1 show the genotype frequencies of $A G T$, GNB3 and CYP3A5 polymorphisms for two Polynesian populations (Nuku'alofa and Ha'apai), one Micronesian population (Ravaki), three AN-speaking Melanesian populations (Kusaghe, Munda and Manus) and one NAN-speaking Melanesian population (Gidra). In the NAN-speaking population, ancestral alleles (rs699-C and rs5051-T) only were found for rs699 and rs5051. These ancestral alleles were also the major alleles in all AN-speaking populations. The ancestral allele homozygote at rs5049 (rs5049-G/G) was more frequent in Melanesia AN-speaking populations (78.1\%, Balopa; 86.0\%, Paradise; $87.4 \%$, Munda) than in non-Melanesian AN-speaking populations (58.6\%, Ravaki; 44.7\% Ha'apai; 59.4\% Nuku'alofa). The derived alleles at rs5443 and rs776746 (rs5443-T and rs776746-G) were more frequent than the ancestral alleles (rs5443-C and rs776746-A) in all populations. No significant deviations from Hardy-Weinberg equilibrium were observed, except for the rs5049 in the Nuku'alofa population. Significant associations were found between rs699 and rs5049 (Fisher's exact test $P<0.0001$ ), rs699 and rs5051 $(P<0.0001)$, and rs5049 and rs5051 $(P<0.0001)$; that is, among SNPs in the AGT gene.

The relationships between distances from the equator (absolute degrees) and the frequencies of ancestral alleles are shown in Figure 2. In the $A G T$ gene, significant negative correlations were found for rs699-C $\quad(r=-0.70, \quad P<0.0001)$ and rs5051-T $\quad(r=-0.72$, $P<0.0001)$, whereas no correlation was found for rs5049-G. A positive correlation was found for rs5443-C in the GNB3 gene $(r=0.83, P<0.0001)$, and a negative correlation was found for rs776746-A in the CYP3A5 gene $(r=-0.59, P<0.0001)$. Within the Pacific Island populations, however, no correlations were observed for ancestral alleles at any of the genotyped SNPs. In addition, the frequencies of ancestral alleles of the Pacific Island populations showed small range variations for rs699 (range: 0.80-1), rs5049 (0.76-0.95), rs5051 (0.81-1) and rs5443 (0.36-0.42); when Gidra (NAN-speaking Melanesian) and Munda (AN-speaking Melanesian) were excluded, the ranges became smaller $(0.80-0.96$ for rs699, $0.76-$ 0.92 for rs5049, $0.81-0.95$ for rs5051 and $0.38-0.42$ for rs5443).

Health status data for each of the Solomon Islands Melanesian populations are summarized in Table 2. There were no differences observed in body height between the populations, but both body weight and BMI were greater for the male and female individuals in Munda town than for those in Kusaghe. SBP and DBP were higher in Munda (127.0 $\mathrm{mm} \mathrm{Hg}$ and $77.3 \mathrm{~mm} \mathrm{Hg}$ on average, respectively) than
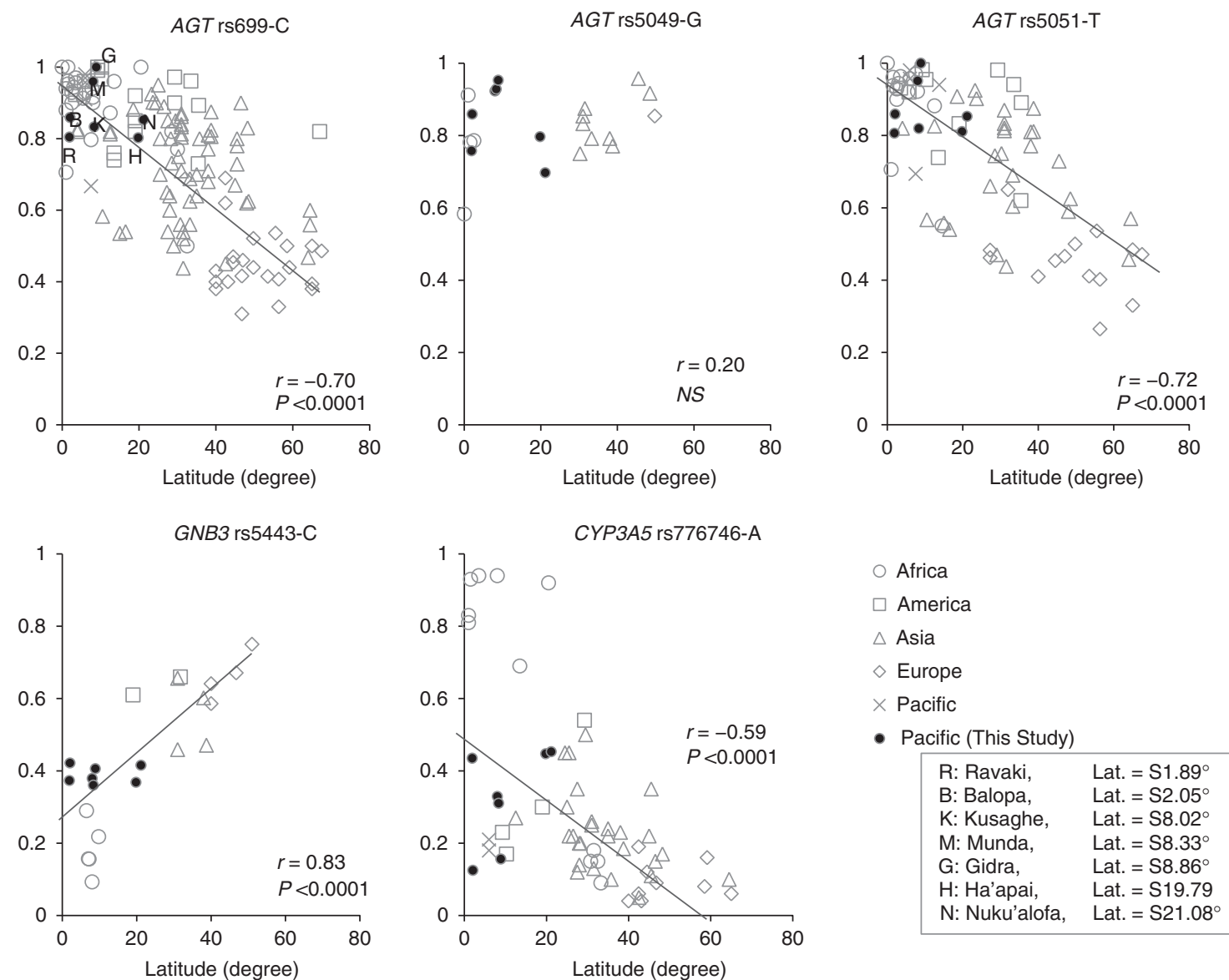

Figure 2 Correlations between the prevalences of the ancestral alleles (rs699-C, rs5049-G, rs5051-T, rs5443-C or rs776746-A) and the distances from the equator. 
Table 2 Characteristics of the participants in the Melanesian Solomon Islands populations

\begin{tabular}{|c|c|c|c|}
\hline & Kusaghe & Munda & $P$ \\
\hline No. of participants ( $\%$ females) & $209(50.7)$ & $174(52.9)$ & \\
\hline Age, years [s.d.] (min-max) & 37.2 [13.7] (18-74) & 44.8 [14.5] (18-79) & $<0.0001$ \\
\hline \multicolumn{4}{|l|}{ Height, $\mathrm{cm}$ (s.d.) } \\
\hline Male & $163.7(5.5)$ & $164.9(5.6)$ & NS \\
\hline Female & $154.9(5.0)$ & $154.6(4.9)$ & NS \\
\hline Male & $61.9(6.2)$ & $67.7(13.8)$ & 0.0006 \\
\hline Female & $60.0(7.9)$ & $63.3(12.5)$ & 0.032 \\
\hline \multicolumn{4}{|l|}{$B M I, \mathrm{kgm}^{-2}$ (s.d.) } \\
\hline Male & 23.1 (1.9) & $24.9(4.7)$ & 0.0017 \\
\hline Female & $25.0(2.9)$ & $26.5(5.1)$ & 0.015 \\
\hline \multicolumn{4}{|l|}{$S B P, m m H g$ (s.d.) } \\
\hline \multicolumn{4}{|l|}{$D B P, m m H g$ (s.d.) } \\
\hline Male & $66.6(7.7)$ & 77.3 (11.9) & $<0.0001$ \\
\hline Female & $76.0(8.6)$ & $79.1(11.1)$ & 0.034 \\
\hline \multicolumn{4}{|l|}{ Prevalence of hypertension } \\
\hline $18-30$ & $2 / 77(2.6 \%)$ & $2 / 29(6.9 \%)$ & NS \\
\hline $30-50$ & $7 / 90(7.8 \%)$ & $9 / 74(12.2 \%)$ & NS \\
\hline $50-$ & $9 / 42(21.4 \%)$ & $29 / 71(42.3 \%)$ & 0.041 \\
\hline Total & $18(8.6 \%)$ & $40(23.0 \%)$ & $<0.0001$ \\
\hline
\end{tabular}

Abbreviations: BMI, body mass index; DBP, diastolic blood pressure; NS, not significant; SBP, systolic blood pressure.

in Kusaghe $(116.9 \mathrm{~mm} \mathrm{Hg}$ and $66.6 \mathrm{~mm} \mathrm{Hg})$ in the male individuals $(P=0.0001$ and $<0.0001)$; however, in the female individuals, a significant difference was found only in DBP $(79.1 \mathrm{vs} 76.0 \mathrm{~mm} \mathrm{Hg}$, $P=0.034)$. Participants' ages were biased between the two populations; the average age was higher in Munda ( 44.8 years) than in Kusaghe (37.8 years). The prevalence of hypertension was significantly higher in Munda $(40 / 174,23.0 \%)$ than in Kusaghe $(18 / 209,8.6 \%)$ $(P<0.0001)$. This prevalence was higher in Munda than Kusaghe for all age groups $(6.9 \%(2 / 29)$ vs $2.6 \%(2 / 77)$ in individuals $18-30$ years of age; $12.2 \%$ (9/74) vs $7.8 \%$ (7/90) in individuals $30-50$ years of age; $42.3 \%(29 / 71)$ vs $21.4 \%$ (9/42) in individuals $\geqslant 50$ years of age), but a significant difference was only found in the elderly.

Table 3 shows the effects of genotypes on hypertension (SBP $\geqslant 140$ $\mathrm{mm} \mathrm{Hg}$ and/or DBP $\geqslant 90 \mathrm{~mm} \mathrm{Hg}$ ); effects of well-known confounding factors (that is, age, gender, BMI and population difference) ${ }^{1-3}$ were adjusted in the logistic regression models. The model fitness indicators (Wald-statistics, likelihood ratios, deviance/the degree of freedom, Pearson residual/the degree of freedom, and HosmerLemeshow Goodness of Fitness) suggested good fitness of each model. The rs5049-A/A genotype (derived allele homozygote) significantly increased the risk of hypertension $(P=0.025)$; however, none of the other SNPs exerted significant effects on disease risk. As shown in Table 4, the effect of rs5049-AA was only significant under the recessive model $(\mathrm{G} / \mathrm{G}+\mathrm{G} / \mathrm{A}$ vs $\mathrm{AA})(P=0.022)$, but not under the dominant model. Although not tabulated, the effects of rs5049 was significant only for $\geqslant 140 \mathrm{~mm} \mathrm{Hg}$ SBP but not for $\geqslant 90 \mathrm{~mm} \mathrm{Hg}$ DBP; other genotypes were neither associated with $\geqslant 140 \mathrm{~mm} \mathrm{Hg}$ SBP nor $\geqslant 90 \mathrm{~mm} \mathrm{Hg}$ DBP. Figure 3 shows values of SBP and DBP separately for different genotypes after adjusting for age, gender, BMI and population in analyses of covariance models; $P$-values were $<0.0001$ for each model. For rs699, individuals with the $\mathrm{C} / \mathrm{T}$ genotype had higher SBP values than those with the T/T genotype did (Tukey's post hoc test $P=0.034$ ). For rs5051, carriers of the ancestral T allele had higher SBP values than individuals with the $\mathrm{C} / \mathrm{C}$ genotype did $(P=0.031$ for $\mathrm{T} / \mathrm{T}$ vs $\mathrm{C} / \mathrm{C}$ and $P=0.028$ for $\mathrm{T} / \mathrm{C}$ vs $\mathrm{C} /$ C). Genotypes at rs5049 did not have any effect on either SBP or DBP.

Strong linkage disequilibrium (i.e., $\left|D^{\prime}\right| \approx 1$ ) was observed between the SNPs rs699 and rs5049 $\left(\left|D^{\prime}\right|=1, r^{2}=0.009\right)$, rs699 and rs5051 $\left(\left|D^{\prime}\right|=0.97, r^{2}=0.86\right)$ and $r 55049$ and rs5051 $\left(\left|D^{\prime}\right|=1, r^{2}=0.026\right)$, i.e., among SNPs in the AGT gene. The stepwise selection of factors by using the general linear models, which included these three SNPs and the other two SNPs (rs5443 and rs776746), as well as age, gender, BMI and population differences revealed a negative effect of the rs5051-C/C genotype $(P=0.034)$ on SBP; age and BMI were also significant predictors of SBP (model $R^{2}=0.20, P<0.0001$ ). In contrast, results from the multiple logistic regression model suggested that the rs5049A/A genotype (odds ratio $=10.31$ (1.59: 67.00), $P=0.015$, as well as age and BMI were significant predictors of hypertension.

\section{DISCUSSION}

Previous studies had suggested that the SNPs analyzed in this study were related to latitude, because certain genotypes had protective roles in high-temperature environments; in African, European, Asian and American populations, ancestral alleles at rs699 and rs5051 in AGT, and rs776746 in CYP3A5, were found to be frequent in lower latitudes, whereas those at rs5443 in GNB3 were found to be more 
Table 3 Odds ratios $(95 \% \mathrm{CI})$ of the effects of $A G T$, GNB3 or CYP3A5 polymorphisms and confounding factors on hypertension $\left(\mathrm{SBP} \geqslant 140 \mathrm{~mm} \mathrm{Hg}\right.$ and/or DBP $\geqslant 90 \mathrm{~mm} \mathrm{Hg}$ ) in the Melanesian Solomon Islands populations ${ }^{\mathrm{a}, \mathrm{b}}$

\begin{tabular}{|c|c|c|c|c|c|c|c|}
\hline Gene (SNP) & & $\begin{array}{l}\text { Allele (homozygote of } \\
\text { ancestral allele }=1 \text { ) }\end{array}$ & Age & Gender (female = 1) & $B M I$ & Population (Munda = 1) & $\begin{array}{c}\text { Model Wald } \\
\text { likelihood ratio } \chi^{2}\end{array}$ \\
\hline $\begin{array}{l}\text { AGT } \\
(\mathrm{rs699})\end{array}$ & $\begin{array}{l}\mathrm{C} / \mathrm{C} \\
\mathrm{C} / \mathrm{T} \\
\mathrm{T} / \mathrm{T}\end{array}$ & $\begin{array}{c}1 \\
1.35(0.56: 3.23) \\
0.78(0.13: 4.61)\end{array}$ & $1.08(1.05: 1.10)^{*}$ & $1.44(0.73: 2.84)$ & $1.23(1.13: 1.33)^{*}$ & $1.42(0.69: 2.88)$ & $\begin{array}{l}51.98^{* * *} \\
79.20^{* * *}\end{array}$ \\
\hline $\begin{array}{l}\text { AGT } \\
(\text { rs5049) }\end{array}$ & $\begin{array}{l}G / G \\
G / A \\
A / A\end{array}$ & $\begin{array}{c}1 \\
0.44(0.14: 1.40) \\
8.89(1.32: 60.05)^{* * *}\end{array}$ & $1.08(1.05: 1.11)^{*}$ & $1.37(0.69: 2.71)$ & $1.24(1.14: 1.35)^{*}$ & $1.37(0.68: 2.76)$ & $\begin{array}{l}52.65^{* * *} \\
85.06^{* * *}\end{array}$ \\
\hline $\begin{array}{l}\text { AGT } \\
(\text { rs5051) }\end{array}$ & $\begin{array}{l}\mathrm{T} / \mathrm{T} \\
\mathrm{T} / \mathrm{C} \\
\mathrm{C} / \mathrm{C}\end{array}$ & $\begin{array}{c}1 \\
1.35(0.58: 3.13) \\
0.65(0.11: 3.65)\end{array}$ & $1.08(1.05: 1.10)^{*}$ & $1.41(0.72: 2.79)$ & $1.23(1.13: 1.34)^{*}$ & $1.43(0.70: 2.91)$ & $\begin{array}{l}52.20^{* * *} \\
79.47^{* * *}\end{array}$ \\
\hline $\begin{array}{l}\text { GNB3 } \\
(r s 5443)\end{array}$ & $\begin{array}{l}\mathrm{C} / \mathrm{C} \\
\mathrm{C} / \mathrm{T} \\
\mathrm{T} / \mathrm{T}\end{array}$ & $\begin{array}{c}1 \\
0.46(0.17: 1.25) \\
0.44(0.16: 1.23)\end{array}$ & $1.08(1.05: 1.11)^{*}$ & $1.40(0.71: 2.75)$ & $1.24(1.14: 1.35)^{*}$ & $1.42(0.71: 2.86)$ & $\begin{array}{l}52.40^{* * *} \\
81.16^{* * *}\end{array}$ \\
\hline $\begin{array}{l}\text { CYP3A5 } \\
\text { (rs776746) }\end{array}$ & $\begin{array}{l}A / A \\
A / G \\
G / G\end{array}$ & $\begin{array}{c}1 \\
1.37(0.42: 4.49) \\
1.69(0.52: 5.44)\end{array}$ & $1.08(1.05: 1.10)^{*}$ & $1.49(0.76: 2.95)$ & $1.22(1.13: 1.33)^{*}$ & $1.44(0.71: 2.90)$ & $\begin{array}{l}52.16^{* * *} \\
79.56^{* * *}\end{array}$ \\
\hline
\end{tabular}

Abbreviations: BMI, body mass index; $\mathrm{Cl}$, confidence interval; DBP, diastolic blood pressure; SBP, systolic blood pressure; SNP, single-nucleotide polymorphism.

$* P<0.05, * * * P<0.0001$

aOdds ratios $(95 \% \mathrm{Cl})$ in a model without genotype differences are $1.07(1.05: 1.10)^{*}, 1.43(0.73: 2.81), 1.22(1.13: 1.33)^{*}$ and $1.47(0.74: 2.93)$ for age, gender, BMI and population,

respectively (model Wald statistic $=51.40(P<0.0001)$, likelihood ratio $\chi^{2}=78.63(P<0.0001)$, the number of unique profile $=383$, deviance/the degree of freedom $=0.65(247.06 / 378)$,

Pearson residual/the degree of freedom $=1.10(416.30 / 378)$, Hosmer-Lemeshow Goodness of Fitness $\left.\chi^{2}=6.48(P=0.5933)\right)$.

bModel fitness indicators for the SNPs rs699, rs5049, rs5051, rs5443 and rs776746 were as follows, respectively: the number of unique profile $=383$ (for all SNPs), deviance/the degree of freedom $=0.66(246.50 / 376), 0.64(240.64 / 376), 0.65(246.23 / 376), 0.65(244.53 / 376), 0.65(246.14 / 376)$, Pearson residual/the degree of freedom $=1.06(399.16 / 376), 1.13(426.7 /$ 376), 1.07 (400.69/376), 1.02 (384.62/376), 1.08 (404.75/376), Hosmer-Lemeshow Goodness of Fitness $\chi^{2}=2.96,6.63,2.95,5.96$ and 7.28 ( $P=0.9369,0.5775,0.9375,0.6514$ and 0.5072).

Table 4 Genotype distribution of rs5049 in hypertension participants and normal participants

\begin{tabular}{|c|c|c|c|c|}
\hline & $\begin{array}{c}\text { Hypertension } \\
\text { participants, n } \\
\text { (\%) }\end{array}$ & $\begin{array}{c}\text { Normal } \\
\text { participants, } \mathrm{n} \\
\text { (\%) }\end{array}$ & $\begin{array}{l}\text { Odds ratio } \\
(95 \% C l)^{\mathrm{a}}\end{array}$ & P-value \\
\hline \multicolumn{5}{|l|}{ Genotype } \\
\hline $\mathrm{G} / \mathrm{G}$ & $52(89.7)$ & 279 (85.9) & 1 & \\
\hline $\mathrm{G} / \mathrm{A}$ & $4(6.9)$ & $42(12.9)$ & $\begin{array}{c}0.44 \\
(0.14: 1.40)\end{array}$ & NS \\
\hline $\mathrm{A} / \mathrm{A}$ & $2(3.5)$ & $4(1.2)$ & $\begin{array}{c}8.89 \\
(1.32: 60.05)\end{array}$ & 0.025 \\
\hline \multicolumn{5}{|c|}{ Recessive model } \\
\hline$G / G+G / A$ & $56(96.5)$ & 321 (98.8) & 1 & \\
\hline $\mathrm{A} / \mathrm{A}$ & $2(3.5)$ & $4(1.2)$ & $\begin{array}{c}9.40 \\
(1.39: 63.46)\end{array}$ & 0.022 \\
\hline \multicolumn{5}{|c|}{ Dominant model } \\
\hline $\mathrm{G} / \mathrm{G}$ & $52(89.7)$ & 279 (85.9) & 1 & \\
\hline $\mathrm{G} / \mathrm{A}+\mathrm{A} / \mathrm{A}$ & $6(10.4)$ & $46(14.1)$ & $\begin{array}{c}1.40 \\
(0.52: 3.77)\end{array}$ & NS \\
\hline
\end{tabular}

Abbreviations: $\mathrm{Cl}$, confidence interval; NS, not significant.

${ }^{a}$ Age, gender, BMI and population difference were adjusted in the logistic regression models (see Table 3).

frequent in higher latitudes. ${ }^{7,10}$ The present study is the first to reveal that Pacific Island populations, which are characterized by their relatively recent settlement of the Pacific Islands ( $\sim 2000$ years ago), also follow the same allele-latitude relationship gradient. However, Pacific Island populations' adaptation to the climatic changes following 'out-of-Asia' migration remained unclear because the frequencies were not correlated with the latitude and that the frequencies were at the similar level regardless of large variation in latitude within the Pacific Island populations $\left(1.89^{\circ}-21.08^{\circ}\right)$. In addition, frequencies of risk alleles (ancestral alleles of rs699 and rs5051 and the derived allele of rs5443) of the Pacific Island populations were similar to those of the Asian populations (Figure 2). The NAN-speaking population Gidra, which has spent tens of thousands of years in Melanesia, showed frequencies of risk alleles (or adaptive alleles in those near the equator) as high as those in the African populations, suggesting that this population reflects adaptation in low-latitude Melanesia. In this regard, the frequencies of risk alleles (rs699-C, rs5049-G and rs5051-T) of Munda, which is an AN-speaking Melanesian population, were similar to those of Gidra. Archeological studies and oral history have suggested that the Munda population descended from the Kazukuru population, which has been identified as an extinct NAN-speaking population that lived in the island. ${ }^{21}$ A previous study hypothesized that the adaptation to latitude occurred relatively recently because Native Americans, who also settled in the Americas only recently, followed the global allele-latitude relations; though the correlation within the Native American population seemed not significant. ${ }^{8}$ In summary, although it remains unclear whether or not adaptation to latitude occurs as recently as 2000 years ago; that is, after the 'out-ofAsia' migration into the Pacific Islands, it is reasonable to consider that the Pacific Island populations also experienced adaptation to the climatic changes after the out-of-Africa migration.

Our results of the associations between these SNPs, hypertension and blood pressure seem controversial. Although rs5049-A contributed to the increased risk of hypertension, this SNP was not associated with elevated SBP or DBP in this study; although $33.3 \%$ of the participants with the rs5049-A/A were classified as hypertensive ( $\mathrm{SBP} \geqslant 140 \mathrm{~mm} \mathrm{Hg}$ and/or $\mathrm{DBP} \geqslant 90 \mathrm{~mm} \mathrm{Hg}$ ), blood pressure of the remaining $66.7 \%$ were as low as those of the other genotypes. This discrepancy was thought to be the result of the small number of the 


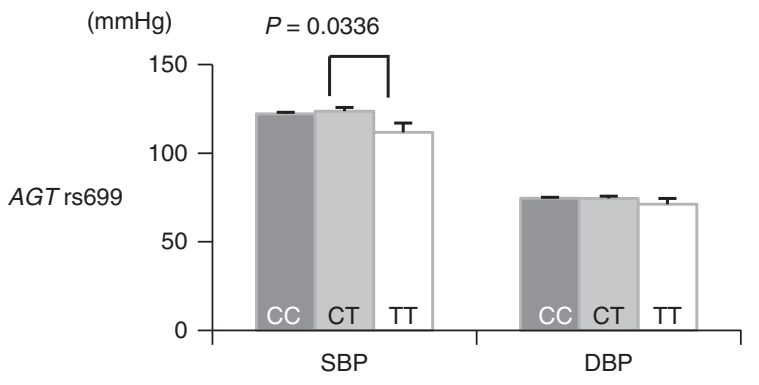

$(\mathrm{mmHg})$

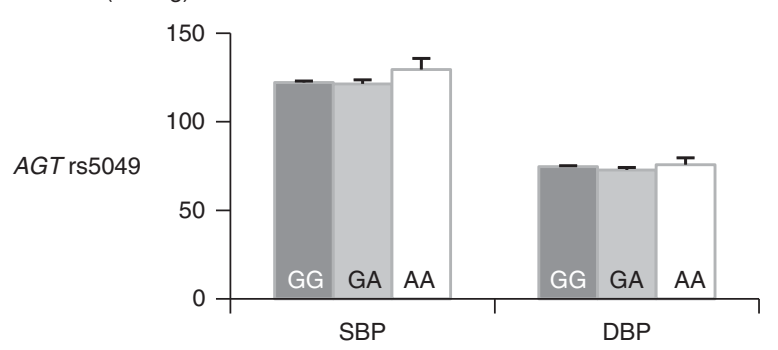

$(\mathrm{mmHg})$

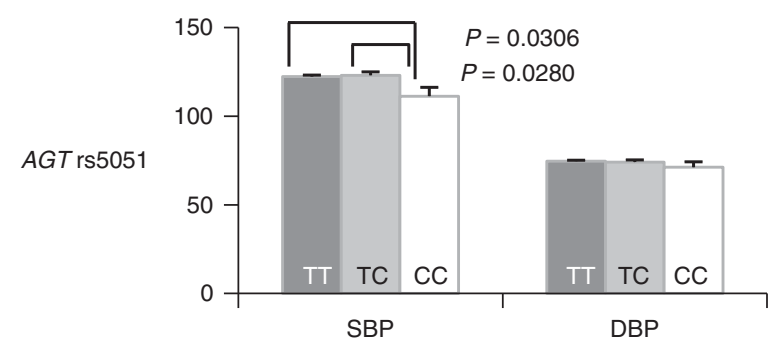

$(\mathrm{mmHg})$
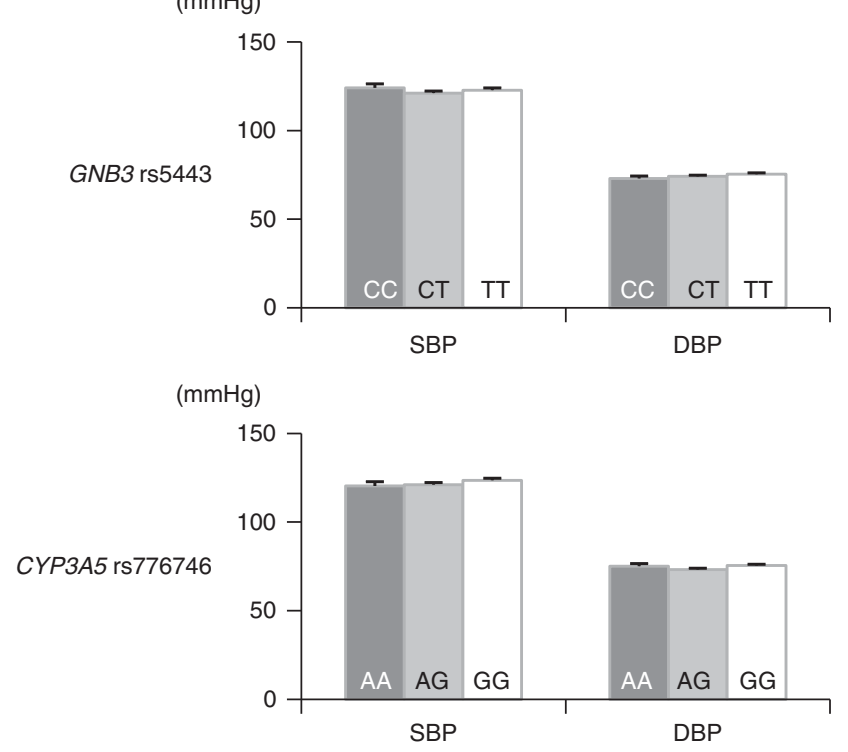

Figure 3 The means and s.e. of SBP and DBP partitioned by AGT, GNB3 and CY3A5 genotypes. Comparisons between every pair of genotypes were made using the analysis of covariance by adjusting for age, gender, BMI and population. P-values for Tukey's post hoc comparison tests are also shown. Note: coefficients (s.e.) for age (years), gender (female=1), BMI and population difference (Munda $=1$ ), respectively, in models without genotype variables were $0.39(0.06)(P<0.0001), 0.047$ (1.611) (NS), $1.04(0.21)$ $(<0.0001)$ and $0.81(1.66)(\mathrm{NS})$ for SBP (model $\left.R^{2}=0.20, P<0.0001\right)$ and $0.15(0.03)(<0.0001), 4.89(0.99)(<0.0001), 0.70(0.13)(<0.0001)$ and $4.41(1.02)(<0.0001)$ for DBP (model $R^{2}=0.28, P<0.0001$ ). participants with the rs5049-A/A genotype. The SNP rs5051, on the other hand, which is in linkage disequilibrium with rs699, was associated with SBP; the derived alleles at rs5051 showed a low frequency but were found to be associated with lower SBP. These findings suggest that the AGT gene had significant roles in the hypertensive traits of the Melanesian Solomon Islanders, although we cannot confirm the specific effect of each SNP. Previous studies also yielded controversial results. The rs699-C (235T) allele was significantly associated with hypertension in European ${ }^{22}$ and Japanese populations, ${ }^{23,24}$ but such an effect was not replicated in an African Caribbean population, in a second European population, or in Malaysians. $^{25-27}$ Although it is possible that the rs5051-T $(-6 \mathrm{G})$ allele is associated with hypertension, the effect of this allele has generally been recognized as a result of strong linkage disequilibrium with rs699. ${ }^{28}$ Unlike rs699 and rs5051, which have been extensively studied, rs5049 has only recently been investigated with respect to hypertension risk; in the present study, we revealed the role of the rs5049-A ( - 217A) allele in hypertension, which is consistent with previous studies in African American and Taiwanese populations, ${ }^{29,30}$ as well as a meta-analysis of six studies. ${ }^{31}$ On the other hand, in other studies, the rs5443-T (825T) allele in GNB3 was previously reported to be associated with hypertension in Europeans ${ }^{32}$ and the male Japanese, ${ }^{33}$ whereas no such association between alleles and hypertension was reported for other populations. ${ }^{34-36}$ Carriers of the rs776746-A allele in CYP3A5 in populations of African origin showed increased blood pressure in previous studies ${ }^{37,38}$ but not in this study. These differences are thought to be caused by other risk factors such as environmental and lifestyle differences, and thus, detailed investigations including not only genetic but also on nongenetic factors are necessary. However, it is noteworthy that all the major alleles in the Pacific Island populations had been previously reported as risk alleles.

It has been suggested that hidden population structure and cryptic relatedness may affect the genetic association studies. ${ }^{39,40}$ As our subjects were recruited from small isolated populations, some subjects might have been close relatives. However, the significant excess of homozygotes was seldom observed at polymorphisms investigated in our study populations, ${ }^{16,41-44}$ although genome-wide analysis using a number of SNPs is necessary to examine the relatedness among our subjects in detail. We therefore judged that cryptic relatedness was only to a limited extent in this study, if any.

The effects of $A G T$, in conjunction with the latitudinal correlation observed here, suggest that genotypes in the Melanesian Solomon Islander populations were positively selected after the out-of-Africa migration ( $\sim 60000$ years ago) into tropical Asia, though effects of the 'out-of-Asia' migration into the Pacific remained unclear. Our previous studies have suggested that carriers of $\mathrm{Q}$ allele of the leptin receptor gene $(L E P R)$ polymorphisms Q223R, who were more common in $\mathrm{AN}$-speaking populations than in NAN-speaking populations, displayed lower serum leptin levels. Lower levels of serum leptin are associated with enhanced food intake and suppressed energy expenditure; thus, not surprisingly, the prevalence of obesity was found to be higher in the AN-speaking populations; this phenotype was thought to have developed after the 'out-of-Asia' migration. ${ }^{16,17}$ Increased risks of non-communicable diseases, including cardiovascular diseases, ${ }^{3,18}$ in the NAN-speaking and AN-speaking Melanesians in urbanized lifestyles are thus thought to have genetic components. Although other polymorphisms associated with hypertension and more populations remain to be studied, findings from the present study, as well as our two previous studies suggest that the susceptibility of Pacific Islanders to many non-communicable 
diseases is the result of human evolution and migration after the outof-African migration, through Asia, into the Pacific Islands. It is thus important to consider the understanding genetics in a population when attempting to understand epidemiological patterns.

In conclusion, this study found that (1) ancestral alleles of rs699, rs5051 and rs776746, and the derived allele of rs5443 were as prevalent in Pacific Island populations as in other equatorial populations; (2) rs5049 was not correlated with latitude; (3) the A/A genotype of rs5049 was a risk factor for hypertension in Melanesian Solomon Islanders; and (4) the T/T genotype of rs699 and the C/C genotype of rs5051 were associated with decreased SBP.

\section{ACKNOWLEDGEMENTS}

This study was financially supported by the KAKENHI Grant-in-Aid for Scientific Research of the Ministry of Education, Culture, Sports, Science and Technology, Japan. We thank the people of the Solomon Islands, Tonga and Papua New Guinea for their kind approval and support of our research. We also thank Dr Taniela Palu, at the Diabetes Clinic; Dr Viliami Tangi, the former Minister of Health for the Kingdom of Tonga; and Prof Kazumichi Katayama, at Kyoto University for their cooperation in the study of the Tongan populations. We also thank the chiefs; elders; and church leaders; especially Sir Ikan Rove of the Christian Fellowship Church of the Solomon Islands; and staff of the National Gizo Hospital and Helena Goldie Hospital for their help with the surveys in the Solomon Islands. We are also grateful to the Department of Human Ecology at the University of Tokyo, Japan.

$1 \mathrm{WHO} / \mathrm{ISH}$. World Health Organization (WHO)/International Society of Hypertension (ISH) statement on management of hypertension. J. Hypertens. 21, 1983-1992 (2003).

2 Eason, R. J., Pada, J., Wallace, R., Henry, A. \& Thornton, R. Changing patterns of hypertension, diabetes, obesity and diet among Melanesians and Micronesians in the Solomon Islands. Med. J. Aust. 146, 465-469 (1987).

3 Natsuhara, K., Inaoka, T., Umezaki, M., Yamauchi, T., Hongo, T., Nagano, M. et al. Cardiovascular risk factors of migrants in Port Moresby from the highlands and island villages, Papua New Guinea. Am. J. Hum. Biol. 12, 655-664 (2000).

4 Marteau, J. B., Zaiou, M., Siest, G. \& Visvikis-Siest, S. Genetic determinants of blood pressure regulation. J. Hypertens. 23, 2127-2143 (2005).

5 Langaee, T., Gong, Y., Yarandi, H., Katz, D., Cooper-DeHoff, R., Pepine, C. et al. Association of CYP3A5 polymorphisms with hypertension and antihypertensive response to verapamil. Clin. Pharmacol. Ther. 81, 386-391 (2007).

6 Watson, R. E., Karnchanasorn, R. \& Gossain, V. V. Hypertension in Asian/Pacific Island Americans. J. Clin. Hypertens. 11, 148-152 (2009).

7 Young, J. H. Evolution of blood pressure regulation in humans. Curr. Hypertens. Rep. 9, 13-18 (2007)

8 Young, J. H., Chang, Y. P. C., Kim, J. D. O., Chretien, J. P., Klag, M. J., Levine, M. A. et al. Differential susceptibility to hypertension is due to selection during the out-ofAfrica expansion. PLoS Genet. 1, e82 (2005).

9 Nakajima, T., Wooding, S., Sakagami, T., Emi, M., Tokunaga, K., Tamiya, G. et al. Natural selection and population history in the human angiotensinogen gene (AGT): 736 complete AGT sequences in chromosomes from around the world. Am. J. Hum. Genet. 74, 898-916 (2004).

10 Thompson, E., Kuttab-Boulos, H., Witonsky, D., Yang, L., Roe, B. \& Di Rienzo, A. CYP3A variation and the evolution of salt-sensitivity variants. Am. J. Hum. Genet. 75, 1059-1069 (2004).

11 Neel, J. V. Diabetes mellitus: a 'thrifty' genotype rendered detrimental by 'progress'? Am. J. Hum. Genet. 14, 353-362 (1962).

12 Diamond, J. M. Express train to Polynesia. Nature 336, 307-308 (1988).

13 Friedlaender, J. S., Friedlaender, F. R., Reed, F. A., Kidd, K. K., Kidd, J. R., Chambers, G. K. et al. The genetic structure of Pacific Islanders. PLoS Genet. 4, e19 (2008).

14 Kimura, R., Ohashi, J., Matsumura, Y., Nakazawa, M., Inaoka, T., Ohtsuka, R. et al. Gene flow and natural selection in oceanic human populations inferred from genomewide SNP typing. Mol. Biol. Evol. 25, 1750-1761 (2008).

15 Oppenheimer, S. J. \& Richards, M. Polynesian origins. Slow boat to Melanesia? Nature 410, 166-167 (2001).

16 Furusawa, T., Naka, I., Yamauchi, T., Natsuhara, K., Kimura, R., Nakazawa, M. et al. The Q223R polymorphism in LEPR is associated with obesity in Pacific Islanders. Hum. Genet. 127, 287-294 (2010).
17 Furusawa, T., Naka, I., Yamauchi, T., Natsuhara, K., Kimura, R., Nakazawa, M. et al. The serum leptin level and body mass index in Melanesian and Micronesian Solomon Islanders: focus on genetic factors and urbanization. Am. J. Hum. Biol. 23, 435-444 (2011).

18 Furusawa, T., Furusawa, H., Eddie, R., Tuni, M., Pitakaka, F. \& Aswani, S. Communicable and non-communicable diseases in the Solomon Islands villages during recovery from a massive earthquake in April 2007. N. Z. Med. J. 124, 17-28 (2011).

19 Page, L., Damon, A. \& Moellering, R. C. Antecedents of cardiovascular disease in six Solomon Islands societies. Circulation 49, 1132-1146 (1974).

20 Weiner, J. S. \& Lourie, J. A. Practical Human Biology (Academic Press, London, 1981).

21 Aswani, S. Common property models of sea tenure: a case study from the Roviana and Vonavona Lagoons, New Georgia, Solomon Islands. Hum. Ecol. 27, 417-453 (1999).

22 Jeunemaitre, X., Soubrier, F., Kotelevtsev, Y. V., Lifton, R. P., Williams, C. S., Charru, A. et al. Molecular basis of human hypertension: role of angiotensinogen. Cell 71, 169-180 (1992).

23 Hata, A., Namikawa, C., Sasaki, M., Sato, K., Nakamura, T., Tamura, K. et al. Angiotensinogen as a risk factor for essential hypertension in Japan. J. Clin. Invest. 93, 1285-1287 (1994).

24 Kato, N., Sugiyama, T., Morita, H., Kurihara, H., Yamori, Y. \& Yazaki, Y. Angiotensinogen gene and essential hypertension in the Japanese: extensive association study and meta-analysis on six reported studies. J. Hypertens. 17, 757-763 (1999).

25 Caulfield, M., Lavender, P., Farrall, M., Munroe, P., Lawson, M., Turner, P. et al. Linkage of the angiotensinogen gene to essential hypertension. N. Engl. J. Med. 330, 1629-1633 (1994).

26 Caulfield, M., Lavender, P., Newell-Price, J., Farrall, M., Kamdar, S., Daniel, H. et al. Linkage of the angiotensinogen gene locus to human essential hypertension in African Caribbeans. J. Clin. Invest. 96, 687-692 (1995).

27 Ghazali, D. M., Rehman, A. \& Rahman, A. R. A. Candidate gene polymorphisms and their association with hypertension in Malays. Clin. Chim. Acta. 388, 46-50 (2008).

28 Inoue, I., Nakajima, T., Williams, C. S., Quackenbush, J., Puryear, R., Powers, M. et al. A nucleotide substitution in the promoter of human angiotensinogen is associated with essential hypertension and affects basal transcription in vitro. J. Clin. Invest. 99, 1786-1797 (1997).

29 Wu, D. M., Shen, M. H. \& Chu, N. F. Relationship between plasma leptin levels and lipid profiles among school children in Taiwan: The Taipei Children Heart Study. Eur. J. Epidemiol. 17, 911-916 (2001).

30 Wu, S. J., Chiang, F. T., Jiang, J. R., Hsu, K. L., Chern, T. H. \& Tseng, Y. Z. The G-217A variant of the angiotensinogen gene affects basal transcription and is associated with hypertension in a Taiwanese population. J. Hypertens. 21, 2061-2067 (2003).

31 Pereira, T. V., Nunes, A. C. F., Rudnicki, M., Yamada, Y., Pereira, A. C. \& Krieger, J. E. Meta-analysis of the association of 4 angiotensinogen polymorphisms with essential hypertension. Hypertension 51, 778-783 (2008).

32 Siffert, W., Rosskopf, D., Siffert, G., Busch, S., Moritz, A., Erbel, R. et al. Association of a human G-protein $\beta 3$ subunit variant with hypertension. Nat. Genet. 18, 45-48 (1998).

33 Izawa, H., Yamada, Y., Okada, T., Tanaka, M., Hirayama, H. \& Yokota, M. Prediction of genetic risk for hypertension. Hypertension 41, 1035-1040 (2003).

34 Brand, E., Herrmann, S. M., Nicaud, V., Ruidavets, J. B., Evans, A., Arveiler, D. et al. The $825 \mathrm{C} / \mathrm{T}$ polymorphism of the $\mathrm{G}$-protein subunit $B 3$ is not related to hypertension. Hypertension 33, 1175-1178 (1999).

35 Huang, X., Ju, Z., Song, Y., Zhang, H., Sun, K., Lu, H. et al. Lack of association between the $G$ protein $B 3$ subunit gene and essential hypertension in Chinese: a casecontrol and a family-based study. J. Mol. Med. 81, 729-735 (2003).

36 Snapir, A., Heinonen, P., Tuomainen, T. P., Lakka, T. A., Kauhanen, J., Salonen, J. T. et al. G-protein beta3 subunit C825T polymorphism: no association with risk for hypertension and obesity. J. Hypertens. 19, 2149-2155 (2001).

37 Bochud, M., Eap, C. B., Elston, R. C., Bovet, P., Maillard, M., Schild, L. et al. Association of CYP3A5 genotypes with blood pressure and renal function in African families. J. Hypertens. 24, 923-929 (2006).

38 Givens, R. C., Lin, Y. S., Dowling, A. L. S., Thummel, K. E., Lamba, J. K., Schuetz, E. G. et al. CYP3A5 genotype predicts renal CYP3A activity and blood pressure in healthy adults. J. Appl. Physiol. 95, 1297-1300 (2003).

39 Huyghe, J. R., Fransen, E., Hannula, S., Van Laer, L., Van Eyken, E., Mäki-Torkko, E. et al. A genome-wide analysis of population structure in the Finnish Saami with implications for genetic association studies. Eur. J. Hum. Genet. 19, 347-352 (2011).

40 Voight, B. F. \& Pritchard, J. K. Confounding from cryptic relatedness in case-control association studies. PLoS Genet. 1, e32 (2005).

41 Fujimoto, A., Kimura, R., Ohashi, J., Omi, K., Yuliwulandari, R., Batubara, L. et al. A scan for genetic determinants of human hair morphology: EDAR is associated with Asian hair thickness. Hum. Mol. Genet. 17, 835-843 (2008).

42 Ohashi, J., Naka, I., Kimura, R., Natsuhara, K., Yamauchi, T., Furusawa, T. et al. FTO polymorphisms in oceanic populations. J. Hum. Genet. 52, 1031-1035 (2007).

43 Ohashi, J., Naka, I., Kimura, R., Tokunaga, K., Yamauchi, T., Natsuhara, K. et al. Polymorphisms in the ABO blood group gene in three populations in the New Georgia group of the Solomon Islands. J. Hum. Genet. 51, 407-411 (2006).

44 Naka, I., Ohashi, J., Kimura, R., Furusawa, T., Yamauchi, T., Nakazawa, M. et al. DRD4 VNTR polymorphism in Oceanic populations. Anthropol. Sci. 120, 151-155 (2012). 